\title{
SINAIS DE FUNDO EM ANÁLISE INSTRUMENTAL: UMA DISCUSSÃO ESSENCIAL EM CURSOS DE GRADUAÇÃO
}

\author{
Renata S. Amais ${ }^{\mathrm{a}}$, Fábio R. P. Rocha ${ }^{\mathrm{a}, *}$ e Joaquim A. Nóbrega ${ }^{\mathrm{b}}$ \\ ${ }^{a}$ Centro de Energia Nuclear na Agricultura, Universidade de São Paulo, 13416-000 Piracicaba - SP, Brasil \\ bDepartamento de Química, Universidade Federal de São Carlos, Caixa Postal 676, 13560-970 São Carlos - SP, Brasil
}

Recebido em 29/05/2016; aceito em 04/10/2016; publicado na web em 26/10/2016

\begin{abstract}
BACKGROUND SIGNALS IN INSTRUMENTAL ANALYSIS: AN ESSENTIAL DISCUSSION IN UNDERGRADUATE COURSES. Understanding instrumental analysis is essential for obtaining reliable analytical results required by chemists in a variety of research areas and industrial activities. All instrumental techniques involve undesirable background (BG) signals originated either from concomitants in the sample or by spurious (e.g. electrical or optical) effects intrinsically related to the measurement process. BG signals may affect accuracy, precision and detection limits. Techniques characterized by low BG stands out by high detectability even when they are based on processes with low efficiency (e.g. low quantum yields and low efficiency of thermal excitation). However, minor attention has been given to this topic in analytical chemistry courses hindering students' understanding of the BG concept and its impact on the analytical performance. Although in some analytical techniques BG is well-defined and successfully compensated, some of them still need further elucidation. Sources of BG and strategies for its minimization and correction are didactically discussed for a variety of analytical techniques, including molecular and atomic spectrometry, electroanalytical methods, and separation techniques. Historical aspects and recent approaches are also addressed.
\end{abstract}

Keywords: Analytical Chemistry; instrumental analysis; background minimization; background correction; spurious signals.

\section{INTRODUÇÃO}

Podemos refletir porque não vemos mais o brilho das estrelas. Estamos muito ocupados ou muito cansados para olhar o céu noturno? Ou estamos muito imersos em um ambiente urbano repleto de luz artificial? Eventualmente ambos os aspectos, mas certamente vivemos em um ambiente repleto de luz. Isso nos recorda o papel de sinais de fundo (BG, do Inglês Background) em análises instrumentais.

Conforme apontado por Lundell em 1933, ${ }^{1}$ não há a necessidade do desenvolvimento de procedimentos analíticos aplicáveis a amostras relativamente simples. Entretanto, em amostras com matrizes complexas, tais como água de mar, fluídos biológicos, solos e sedimentos, espécies concomitantes podem afetar significativamente a geração de sinais analíticos. Adicionalmente, a geração de sinais indesejáveis (i.e. sinais espúrios) pode estar associada à própria medição instrumental.

Neste artigo didático, são discutidos tanto o BG oriundo das matrizes das amostras, quanto aqueles inerentes às técnicas instrumentais. O primeiro grupo se refere a processos que podem resultar em interferências, caso não sejam propriamente eliminados ou corrigidos. Nesse sentido, há interpretações diversas sobre sinais de fundo, dependendo da técnica instrumental. Em algumas delas os processos são bem definidos, enquanto em outras o termo sinal de fundo não é usualmente relacionado aos sinais espúrios que afetam a medida analítica.

O desenvolvimento de um procedimento analítico requer estratégias para maximizar o sinal analítico e, ao mesmo tempo, minimizar o BG. Adicionalmente, na medida instrumental, o BG residual deve ser corrigido, visando à correlação do sinal analítico (i.e. sinal líquido) com a concentração do analito. Isso é particularmente crítico quando concentrações em nível de traços devem ser determinadas em amostras com matrizes complexas. Quando o BG é significativo em comparação ao sinal analítico, mesmo pequenas variações no

*e-mail: frprocha@cena.usp.br sinal espúrio afetam a exatidão. ${ }^{2} \mathrm{O}$ desenvolvimento instrumental permitiu que essas correções geralmente possam ser feitas, mas os analistas devem entender os princípios e as condições de contorno envolvidos. Uma analogia pode ser feita com o uso de uma balança de rodovia para determinar a massa de um motorista, considerando a pesagem do motorista em um caminhão carregado (i.e. sinal total) e a massa do caminhão isoladamente (BG); a massa do motorista (sinal líquido) seria, então, obtida por diferença (i.e. subtração do BG do sinal total). Naturalmente, o valor de massa obtido não seria confiável. Entretanto, frequentemente demandamos algo análogo dos instrumentos analíticos que usamos. A analogia anterior serve também para enfatizar que as incertezas no sinal total e BG afetam o sinal analítico, i.e. os erros correspondentes são propagados.

Nesse contexto, em disciplinas de análise instrumental, uma técnica analítica deveria ser introduzida considerando como o sinal analítico é gerado e medido e como o BG é minimizado e corrigido. É também importante diferenciar BG de ruído. Segundo a IUPAC, ruídos são flutuações aleatórias inerentes ao sinal analítico, devido à combinação de fatores instrumentais e relativos ao método analítico (ruído químico). ${ }^{3}$ É incorreto pensar que o ruído é o sinal de fundo ou apenas flutuação da linha de base sem a presença do analito, visto que o ruído afeta tanto o sinal analítico, quanto o BG. A razão sinal/ ruído $(\mathrm{S} / \mathrm{R})$ é um parâmetro de desempenho que indica a qualidade de uma medida analítica e razões superiores a 3 são recomendadas para garantir a precisão e a exatidão analítica. Assim, é importante reconhecer as fontes de ruído, destacadas no esquema mostrado na Figura 1, a fim de minimizar a sua magnitude e aumentar a razão S/R.

Enquanto os ruídos químicos são resultado de variações nas propriedades químicas ou físicas da amostra, em consequência de variações de parâmetros experimentais, como temperatura, pressão e umidade, o ruído instrumental é mais complexo. Esse deve-se ao caráter aleatório do movimento dos elétrons nos circuitos elétricos que acompanham movimentos térmicos dos átomos, levando às flutuações de tensão na presença de um elemento resistivo (térmico ou de Johnson), ou dos elétrons cruzando junções ou superfícies 


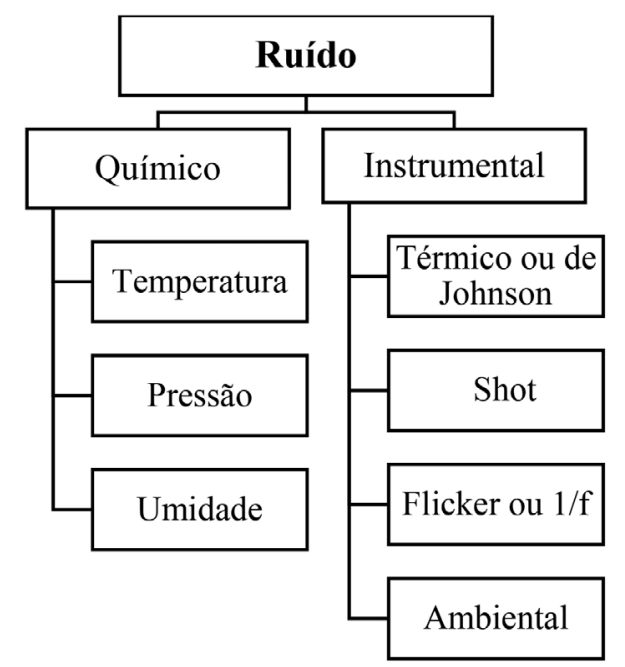

Figura 1. Classificação do ruído de acordo com sua fonte

independentemente da frequência e com comportamento quantizados, também de caráter aleatório (Shot, e.g. ruído da corrente de escuro ou derivado de fótons, elétrons e íons quando atingem o detector de massas, ambos discutidos mais adiante). O ruído Flicker é inversamente proporcional à frequência do sinal e, por isso, também conhecido como 1/f. Geralmente é causado por defeitos nos materiais do instrumento e rugosidades de interface, $e$.g. ruídos provenientes de flutuações associadas ao processo de introdução de amostras, o qual pode ser compensado com o uso do método de padronização interna. ${ }^{4} \mathrm{O}$ ruído ambiental é principalmente consequência do chamado "efeito antena", em que diversas radiações eletromagnéticas podem ser captadas e transformadas em sinais elétricos. Nesse caso, o ruído é dependente da frequência. Recomenda-se a consulta a livros texto de análises instrumentais para uma discussão mais detalhada sobre ruídos. ${ }^{5}$

Este artigo discute didaticamente as fontes de BG em diferentes técnicas instrumentais, assim como estratégias para minimizar e corrigir os sinais espúrios (Tabela 1). Pretende-se demonstrar que o BG é um conceito central em análise instrumental, frequentemente sendo o fator limitante para alcançar resultados confiáveis. Essa discussão é, entretanto, frequentemente negligenciada em livros texto e na discussão de algumas técnicas instrumentais. A discussão é apropriada para estudantes em final de curso de graduação ou em disciplinas de pós-graduação. Neste sentido, palavras-chave relacionadas a conceitos que deveriam ser previamente entendidos são sublinhadas no texto. Isso também permite uma revisão dos conceitos essenciais de diversas técnicas instrumentais.

\section{ESPECTROMETRIA ATÔMICA}

\section{Espectrometria de absorção atômica}

A espectrometria de absorção atômica (AAS) é baseada na absorção de radiação de comprimento de onda específico (na faixa UV-vis) por uma nuvem atômica formada a partir da amostra. Conforme pioneiramente expresso por Bunsen e Kirchhoff, cada átomo é capaz de absorver a própria radiação emitida no decaimento do estado excitado e a lei de Lambert-Beer estabelece que a absorvância é linearmente proporcional à concentração dos átomos na nuvem e, portanto, na amostra original. Para a formação da nuvem atômica de quase todos os elementos, exceto $\mathrm{Hg}$, é necessário o aumento de temperatura. Essa tarefa é realizada por atomizadores, sendo os mais usuais as chamas e dispositivos eletrotérmicos, tais como fornos de grafite ou metálicos.

Tabela 1. Sinais de fundo (BG) em diferentes técnicas analíticas

\begin{tabular}{|c|c|c|}
\hline Técnica $^{a}$ & Fonte de BG & Alternativa para superar ou corrigir o BG \\
\hline AAS & Espalhamento de radiação e absorção molecular & $\begin{array}{l}\text { Condições STPF e corretores baseados em fonte contínua, aplicação de } \\
\text { um pulso de alta corrente na fonte de radiação ou efeito Zeeman }\end{array}$ \\
\hline WCAES & $\begin{array}{l}\text { Emissão pelo filamento incandescente (corpo } \\
\text { negro) e por moléculas excitadas formadas por } \\
\text { processos de recombinação devido ao gradiente } \\
\text { de temperatura }\end{array}$ & Separação temporal do sinal analítico e BG \\
\hline LIBS & Emissão de sinal contínuo pelo plasma ${ }^{b}$ & Separação temporal do sinal analítico e BG \\
\hline ICP OES & Emissão de sinal contínuo pelo plasma ${ }^{b}$ & $\begin{array}{l}\text { Condição de operação do plasma e medidas laterais às linhas de emissão } \\
\text { do analito para correção matemática }\end{array}$ \\
\hline FAES & Emissão molecular e da chama & Subtração do BG estimado a partir do sinal da solução de branco \\
\hline ICP-MS & $\begin{array}{l}\text { Íons gerados no ICP a partir do gás do plasma, } \\
\text { solvente e gases atmosféricos }\end{array}$ & $\begin{array}{l}\text { Plasma frio, celas de reação e colisão, analisador de massas de dupla } \\
\text { focalização, photon-stop, deslocamento de eixo e deflexão em } 90^{\circ}\end{array}$ \\
\hline Espectrofotometria UV-vis & $\begin{array}{l}\text { Radiação espúria, corrente de escuro, reflexão nas } \\
\text { paredes da cubeta e espalhamento de radiação }\end{array}$ & $\begin{array}{l}\text { Medições em cubetas similares, compensação da corrente de escuro, } \\
\text { remoção de sólidos em suspensão e espectrofotometria derivativa }\end{array}$ \\
\hline Fotoluminescência & Radiação espúria e corrente de escuro & $\begin{array}{l}\text { Detector localizado perpendicularmente à fonte de radiação, mono- } \\
\text { cromador secundário, compensação de corrente de escuro e separação } \\
\text { temporal do sinal analítico do BG }\end{array}$ \\
\hline GC-FID & Corrente residual de espécies carregadas na chama & Uso de hidrogênio de alta pureza, medida e correção da corrente residual \\
\hline HPLC-UV/CE-UV & $\begin{array}{l}\text { Absorção de radiação pelas espécies presentes na } \\
\text { fase móvel }\end{array}$ & $\begin{array}{l}\text { Uso de solventes e fase móvel com baixa absortividade no comprimento } \\
\text { de onda de interesse }\end{array}$ \\
\hline HPLC-CD & Condutividade de íons do eluente & Colunas de supressão \\
\hline Voltametria & Corrente não Faradaica & Uso de eletrólitos de suporte e técnicas de pulso \\
\hline Potenciometria & $\begin{array}{l}\text { Potencial de junção e de assimetria dos eletrodos } \\
\text { de vidro }\end{array}$ & Uso de íons com mobilidade similar na ponte salina e calibração adequada \\
\hline
\end{tabular}

${ }^{a}$ Siglas são definidas no texto; 'Recombinação do íon argônio e elétron, radiação Bremsstrahlung e emissão de bandas $\left(\right.$ e.g. $\mathrm{OH}, \mathrm{N}_{2}{ }^{+}, \mathrm{NH}$ e $\left.\mathrm{NO}\right)$ 
A radiação incidente pode ser atenuada por absorção atômica (relacionada à concentração do analito), bem como por absorção molecular e processos de espalhamento, esses dois últimos processos constituindo o BG. Os sinais de fundo geralmente não são elevados em atomizadores com chama porque a quantidade da matriz de amostra inserida é relativamente baixa (considerando o volume da chama e a baixa eficiência de nebulização) e a nuvem de vapor formada é dispersa no atomizador. Por outro lado, a contribuição do BG no atomizador eletrotérmico em tubo de grafite (GFAAS) é significativa devido à densidade da nuvem de vapor confinada no interior do tubo. Esse efeito foi observado desde o início da GFAAS e, em 1965, Koirtyohann e Pickett propuseram um corretor de BG com base em uma fonte de radiação contínua. ${ }^{6}$

A magnitude e distribuição temporal do BG fornecem informações importantes sobre o tratamento da amostra em GFAAS. Para uma amostra complexa, como a água de mar, o número de átomos do analito na nuvem pode ser $10^{6}$ vezes inferior ao número de moléculas, o que significa que a magnitude do BG pode ser extremamente superior à intensidade de absorção atômica. Esse foi um fator limitante para a obtenção de resultados exatos e precisos durante mais de duas décadas de desenvolvimento da GFAAS. Essa dificuldade foi superada quando as condições de forno com plataforma e temperatura estabilizada (do inglês Stabilized platform temperature furnace, STPF) foram propostas. ${ }^{7}$ Empregando condições STPF, um modificador químico deve ser adicionado à amostra para favorecer a separação termoquímica entre analito e matriz da amostra, minimizando perdas de analito na etapa de pirólise. O modificador químico pode promover a redução de $\mathrm{BG}$ e/ou interferências promovendo a formação de espécies menos voláteis a partir do analito, tornando concomitantes da matriz mais voláteis, reduzindo a formação de carbetos, modificando a fase gasosa, modificando a superfície do atomizador e alterando mecanismos de atomização. ${ }^{8}$ No entanto, alguns constituintes da matriz residual normalmente permanecem no produto sólido após a etapa de pirólise e, então, é necessário um corretor de BG para compensar o seu efeito sobre a absorvância. O sinal líquido é obtido subtraindo-se o BG do sinal total. Além do corretor baseado em fonte contínua de $\mathrm{D}_{2},{ }^{9}$ outras abordagens incluem a aplicação de um pulso de corrente na fonte de radiação primária (corretor de Smith-Hieftje), ${ }^{10}$ ou um campo eletromagnético intenso contínuo ou alternado em torno da nuvem de vapor. ${ }^{11} \mathrm{O}$ último corretor, baseado no efeito Zeeman, é o mais eficaz para corrigir BG elevados. A comparação dos corretores Zeeman e $\mathrm{D}_{2}$ para a compensação do $\mathrm{BG}$ na determinação de arsênio em água do mar por GFAAS, utilizando $\mathrm{Pd}\left(\mathrm{NO}_{3}\right)_{2}$ como modificador químico, demonstra essa eficácia. ${ }^{12}$ Resultados exatos só foram obtidos com corretor Zeeman, que corrigiu efetivamente o BG causado por cloreto, sódio, potássio, cálcio e silício. Esse corretor também é o único capaz de corrigir $\mathrm{BG}$ estruturado, tal como aquele causado por fosfato sobre a determinação de $\mathrm{Cd}$ e $\mathrm{Pb}$ em baixos comprimentos de onda de absorção. ${ }^{9}$

A AAS com fonte de linhas (lâmpadas que emitem radiação específica para cada elemento) baseia-se na medida de absorção em intervalos espectrais estreitos, definidos pela largura da linha atômica emitida pela fonte de radiação. Assim, informações sobre o ambiente espectral do sinal analítico são significativamente limitadas. Em $\underline{\text { AAS }}$ com fonte contínua e alta resolução, todo o espectro de absorção (190 a $900 \mathrm{~nm}$ ) pode ser visualizado em função do tempo. Os espectros tridimensionais obtidos fornecem informações detalhadas sobre o ambiente espectral do analito, as quais podem ser utilizadas na correção do BG. Considerando-se que até 5 elementos sensores (pixels) são utilizados para medir o sinal de absorção atômica, os pixels vizinhos podem ser utilizados para a correção do BG. Assim, diferentemente do corretor com fonte contínua de $\mathrm{D}_{2}$, BG e sinais analíticos de interesse são medidos simultaneamente. Os algoritmos de mínimos quadrados são uma alternativa para superar BG estruturado, porém, nesse caso é necessário obter o espectro das espécies interferentes (moléculas) separadamente do analito (espectro de referência do interferente constituinte da matriz). ${ }^{13}$

\section{Espectrometria de emissão atômica}

A suposição feita por Kirchhoff e Bunsen, em 1859, de que linhas de emissão finas e bem definidas provenientes das chamas eram produzidas por átomos é um marco para a compreensão da espectrometria de emissão atômica. Todos os elementos atomizados, possivelmente ionizados e, em seguida, excitados por uma fonte externa podem liberar energia na forma de radiação eletromagnética com espectros característicos quando decaem a um estado de menor energia. Na espectrometria de emissão atômica, a intensidade de radiação eletromagnética emitida na região do UV-vis é utilizada para fins quantitativos. Medidas de emissão são baseadas na população de átomos no estado excitado, a qual pode ser estimada pela equação de Boltzmann. ${ }^{9}$ O sinal analítico depende da temperatura do atomizador, que também desempenha um papel importante sobre a emissão do BG. Para todas as temperaturas práticas, a população de átomos no estado fundamental é maior do que no estado excitado.

Os sinais de emissão são facilmente detectados quando o BG é baixo. Uma analogia interessante é a de um estádio repleto de pessoas segurando velas acesas ou não. ${ }^{14}$ No caso de emissão atômica, imagine esse estádio no escuro e em um dado momento uma fração do público acende suas velas. Certamente esse grupo será facilmente identificado, i.e. a luz emitida pode ser facilmente detectada devido ao baixo BG. Uma situação completamente diferente é observada se todas as velas no estádio estiverem acesas e o mesmo pequeno grupo de pessoas apagarem as suas velas (ver também a comparação na Figura 2). Isso ilustra que a variação na emissão é difícil de ser detectada com confiabilidade sob elevada emissão de BG. O mesmo ocorre em outras técnicas baseadas na emissão de radiação. Por exemplo, uma das razões para a utilização de plasma de argônio como fonte de energia na espectrometria de emissão óptica (discutida a seguir) está relacionada com a sua baixa emissão de BG.

As chamas são usadas com sucesso para a excitação de átomos e íons com energia de excitação relativamente baixa. A emissão de
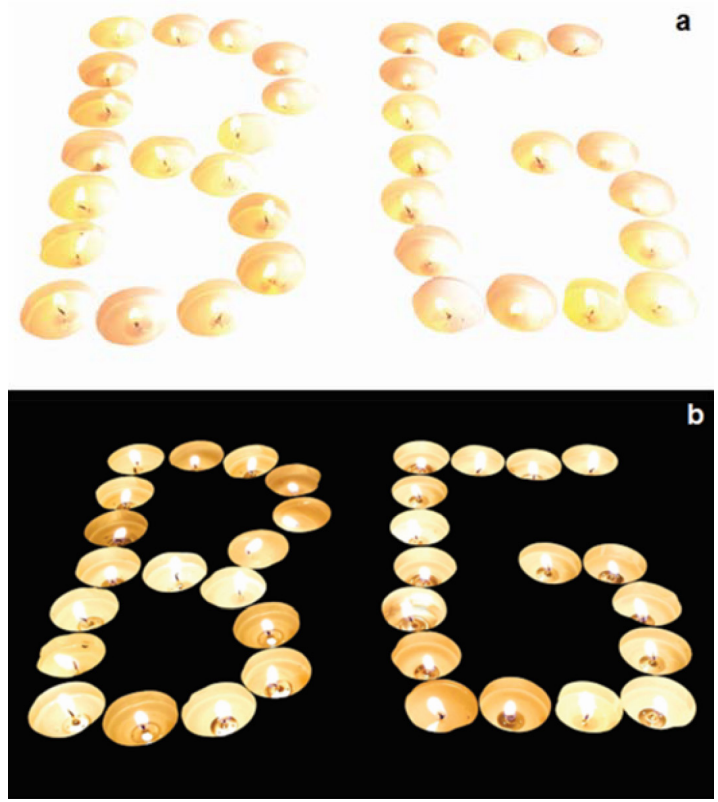

Figura 2. Representação de sinais analíticos medidos em situações de (a) alto e (b) baixo $B G$ 
fundo proveniente da chama e das moléculas geradas no processo de combustão pode ser geralmente corrigida subtraindo o sinal espúrio medido com uma solução de branco analítico, embora haja o inconveniente de que os sinais não são medidos simultaneamente. Ao trabalhar com chamas frias (e.g. combustão de gás propano ou butano com ar) o BG relativamente baixo viabiliza o uso de filtros para discriminar sinais espúrios e analíticos. Entretanto, apenas elementos facilmente excitáveis ( $\mathrm{Li}, \mathrm{Na}$ e $\mathrm{K}$ ) podem ser quantificados nessas condições.

As medições de emissão também podem ser realizadas usando um tubo de grafite como atomizador, mas essa estratégia não é tão atrativa devido à forte emissão gerada pelo tubo incandescente sob altas temperaturas ${ }^{15}$ também denominada emissão de corpo negro. A uma dada temperatura, corpos emitem espectros idênticos independente de sua composição, e a intensidade de radiação foi descrita como função da frequência à temperatura constante pelas leis de Wien e Rayleigh-Jeans. Posteriormente, foi demonstrado que a luminosidade na superfície de um corpo negro é proporcional à quarta potência da temperatura do corpo (lei de Stefan-Boltzmann). Deve ser mencionado que essa intensa emissão de corpo negro é eficazmente corrigida em AAS modulando-se a fonte de radiação, que permite distinguir entre a emissão contínua proveniente do atomizador daquela modulada a uma frequência determinada proveniente da fonte. ${ }^{16}$ Entretanto, essa alternativa não é viável para as medidas de emissão.

$\mathrm{Na}$ espectrometria de emissão óptica com plasma acoplado indutivamente (ICP OES), um espectro de linhas extremamente rico é observado (ver alguns exemplos na Tabela 2). Além disso, a recombinação de íons argônio e elétrons $\left(\mathrm{Ar}^{+}+\mathrm{e}^{-} \rightarrow \mathrm{Ar}+\mathrm{hv}\right)$ e a perda radiante de energia advinda da desaceleração de elétrons (radiação Bremsstrahlung) resultam em um intenso fundo contínuo. ${ }^{17}$ $\mathrm{O}$ primeiro processo resulta em $\mathrm{BG}$ principalmente na região do $\mathrm{UV}$, enquanto o último é mais pronunciado na região do visível. Bandas de emissão molecular de espécies produzidas no plasma a partir de moléculas de água ou gases atmosféricos (e.g. bandas de $\mathrm{OH}, \mathrm{N}_{2}{ }^{+}, \mathrm{NH}$ e NO) também contribuem para o BG em ICP OES, ${ }^{18}$ que também é afetado por variações nos parâmetros instrumentais, como a potência de radiofrequência aplicada e a vazão do gás de nebulização. Embora o BG possa ser reduzido ajustando-se parâmetros instrumentais, não pode ser completamente eliminado.

Avanços no sistema óptico, como a dispersão da radiação UV-vis combinando-se rede Echelle e prisma em detectores de transferência de carga, bem como na tecnologia de processamento de dados, tornaram a correção do $\mathrm{BG}$ em ICP OES mais eficiente e rápida. Essa correção é geralmente realizada através de medições em um ou dois comprimentos de onda de ambos os lados do pico de emissão do analito; em seguida, tratamento adequado de dados é aplicado dependendo do perfil do BG. ${ }^{19}$ A correção efetiva do BG é, por vezes, prejudicada porque o $\mathrm{BG}$ pode ser plano e deslocar-se em paralelo ou variar de forma curva na região do comprimento de onda de interesse, exigindo assim tratamento mais elaborado dos dados.

A visão axial em ICP OES foi proposta em 1976 com o objetivo de melhorar os limites de detecção (LOD), medindo a emissão do analito na região central do plasma orientado horizontalmente. ${ }^{20}$ Entretanto, essa configuração instrumental teve que superar dificuldades como maiores BG e interferências espectrais e de matriz que atrasaram a disponibilidade comercial desses instrumentos em 15 anos. A cauda mais fria do plasma favorece processos de recombinação e efeitos de autoabsorção que também aumentam BG e depreciam o sinal analítico. Assim, melhor desempenho analítico só foi alcançado após o desenvolvimento de interfaces adequadas, e.g. usando fluxo de gás em contracorrente (end-on gas) ou perpendicular (shear gas) em relação ao plasma, ${ }^{21}$ ou interface na forma de cone que desvia a cauda fria do plasma da região de observação. Limites de detecção 5 e 10 vezes menores foram alcançados para $\mathrm{Cd}$ e $\mathrm{Ca}$, respectivamente, em comparação com ICP OES em configuração radial. ${ }^{22}$

Tabela 2. Comparação entre o número de linhas de emissão e isótopos estáveis de alguns elementos ${ }^{35}$

\begin{tabular}{lcc}
\hline Elementos & $\begin{array}{c}\text { Número de } \\
\text { linhas de } \\
\text { emissão* }\end{array}$ & Isótopos estáveis \\
\hline $\mathrm{Ar}$ & 553 & ${ }^{36} \mathrm{Ar},{ }^{38} \mathrm{Ar},{ }^{40} \mathrm{Ar}$ \\
$\mathrm{As}$ & 123 & ${ }^{75} \mathrm{As}$ \\
$\mathrm{Bi}$ & 234 & ${ }^{209} \mathrm{Bi}$ \\
$\mathrm{Cd}$ & 203 & ${ }^{106} \mathrm{Cd},{ }^{108} \mathrm{Cd},{ }^{110} \mathrm{Cd},{ }^{111} \mathrm{Cd},{ }^{112} \mathrm{Cd},{ }^{113} \mathrm{Cd},{ }^{114} \mathrm{Cd}$, \\
$\mathrm{Cr}$ & ${ }^{50} \mathrm{Cr},{ }^{52} \mathrm{Cr},{ }^{53} \mathrm{Cr},{ }^{54} \mathrm{Cr}$ \\
$\mathrm{Fe}$ & 368 & ${ }^{54} \mathrm{Fe},{ }^{56} \mathrm{Fe},{ }^{57} \mathrm{Fe},{ }^{58} \mathrm{Fe}$ \\
$\mathrm{Mo}$ & 1106 & ${ }^{92} \mathrm{Mo},{ }^{94} \mathrm{Mo},{ }^{95} \mathrm{Mo},{ }^{96} \mathrm{Mo},{ }^{97} \mathrm{Mo},{ }^{98} \mathrm{Mo},{ }^{100} \mathrm{Mo}$ \\
$\mathrm{Pb}$ & 218 & ${ }^{204} \mathrm{~Pb},{ }^{206} \mathrm{~Pb},{ }^{207} \mathrm{~Pb},{ }^{208} \mathrm{~Pb}$ \\
$\mathrm{Se}$ & 153 & ${ }^{74} \mathrm{Se},{ }^{76} \mathrm{Se},{ }^{77} \mathrm{Se},{ }^{78} \mathrm{Se},{ }^{80} \mathrm{Se},{ }^{82} \mathrm{Se}$ \\
$\mathrm{V}$ & 216 & ${ }^{50} \mathrm{~V},{ }^{51} \mathrm{~V}$ \\
\hline
\end{tabular}

*Linhas de emissão mais intensas observadas nas regiões do ultravioleta até a região do infravermelho distante.

Menos usual é a utilização de filamento de tungstênio como atomizador eletrotérmico para medidas de emissão atômica, como proposto por Rust et al. ${ }^{23} \mathrm{O}$ baixo custo e a elevada taxa de aquecimento desse dispositivo torna a espectrometria de emissão atômica em filamento de tungstênio (WCAES) atraente. No entanto, existe um elevado gradiente de temperatura entre a superfície do filamento e a fase gasosa. Essa característica favorece processos de recombinação e, então, a emissão de radiação por moléculas. É também significativo o BG em todo espectro UV-vis devido à emissão do próprio atomizador de tungstênio aquecido (incandescência). De acordo com a lei de Stefan-Boltzmann, quanto maior a temperatura do filamento de tungstênio (corpo negro), mais intensa a emissão da radiação de fundo. Apesar dessas dificuldades, a WCAES é viável e sensível para determinação de vários elementos. ${ }^{24} \mathrm{O}$ aspecto fundamental é detectar o sinal analítico no início dos processos de emissão atômica, antes da manifestação de sinais dominantes de BG, como demonstrado em medições das emissões de $\mathrm{Ca}^{25,26} \mathrm{~A}$ separação temporal entre sinal analítico e BG é possível devido ao aquecimento extremamente rápido $(20 \mathrm{~K} / \mathrm{ms})$ relacionado à baixa massa e baixo calor específico do atomizador filamento de tungstênio, o que melhora a razão S/R. Essa estratégia ilustra a separação temporal entre os processos de emissão relacionados com o decaimento de átomos excitados e BG de radiação do corpo negro (Figura $3 a) .{ }^{25}$ Deve ser ressaltado que não há redução ou correção do $\mathrm{BG}$ nessa estratégia, mas a medida da emissão atômica no momento em que a relação sinal analítico/ BG é favorecida.

O contrário é observado na espectrometria de emissão óptica com plasma induzido por laser (LIBS), que também se baseia em medidas de emissão, mas a fonte de energia é um curto pulso de laser que vaporiza a amostra e excita os elementos (e fragmentos moleculares) que irão decair emitindo radiação. ${ }^{27} \mathrm{Um}$ tempo de atraso é necessário para início da medição analítica para evitar a alta emissão contínua (BG) que ocorre no início da formação do plasma $^{28}$ (Figura 3b). Como a diminuição da intensidade de emissão do contínuo do plasma ocorre em uma taxa mais elevada do que a dos átomos ou íons excitados no plasma, a separação temporal é viável. Assim, um fator fundamental e crítico em LIBS (e também em WCAES) é a capacidade instrumental 

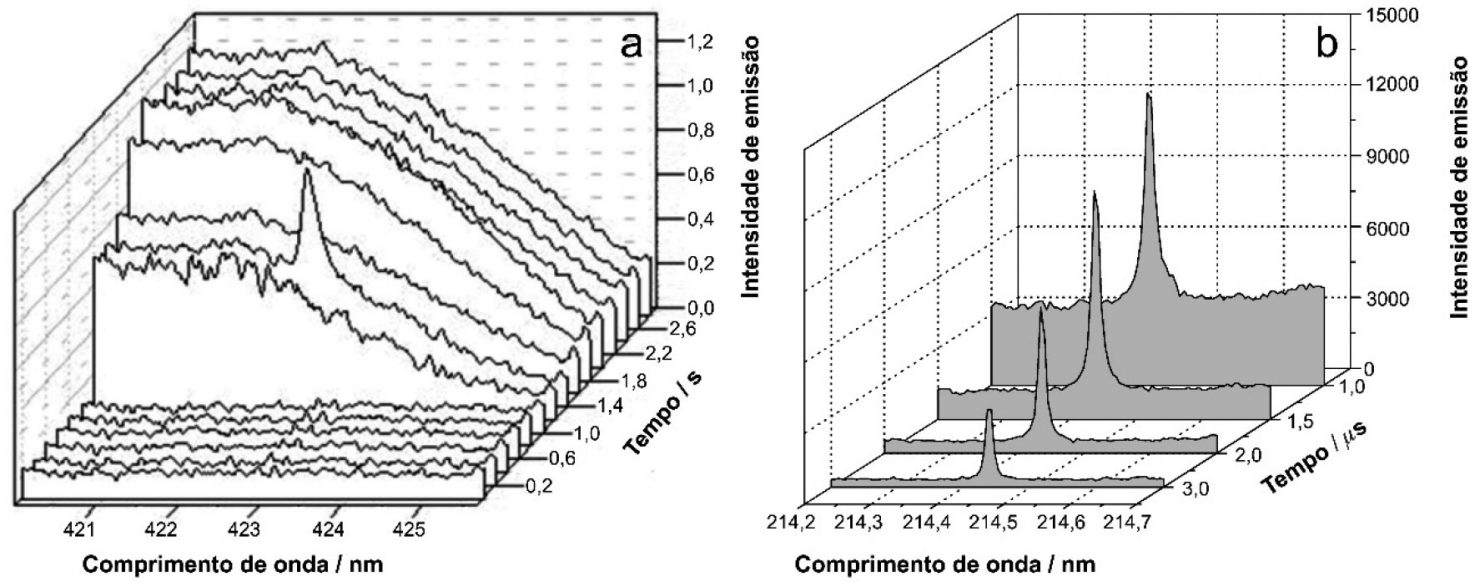

Figura 3. Separação temporal do sinal analítico e intenso BG em WCAES (a) e LIBS (b). Medidas referem-se à determinação de cálcio (a) e cádmio (b). As intensidades de emissão foram medidas em unidades arbitrárias e as escalas de tempo estão em sentidos opostos para maior clareza. A Figura 3 a é reproduzida da referência 26, com permissão da Editora. A Figura 3 b refere-se a resultados não publicados, obtidos em condições similares às descritas na referência 28

de realizar a aquisição de sinal em diferentes tempos de atraso para encontrar o momento ideal para obtenção dos sinais analíticos.

\section{Espectrometria de fluorescência atômica}

A espectrometria de fluorescência atômica (AFS) baseia-se na absorção de radiação característica por vapores atômicos para produzir átomos excitados, com subsequente detecção da radiação emitida nos processos de relaxação, tipicamente a $90^{\circ}$ em relação à fonte de excitação. ${ }^{29}$ Existem três tipos básicos de fluorescência atômica, classificados de acordo com as transições eletrônicas envolvidas: ressonante, não ressonante e termicamente assistida. ${ }^{30}$ $\mathrm{O}$ processo ressonante gera a fluorescência de maior intensidade, sendo o mais explorado para fins analíticos, apesar do maior BG (produzido por espalhamento e radiação difusa da fonte primária) por conta de se medir o sinal analítico no mesmo comprimento de onda da fotoexcitação.

A analogia das velas no estádio lotado também é válida em AFS. Os LODs são apreciáveis especialmente quando AFS é associada à geração de vapores de $\mathrm{As}, \mathrm{Hg}$, Se e Sb. ${ }^{31}$ Em alguns casos, LODs comparáveis à técnica de espectrometria de massas com plasma acoplado indutivamente (ICP-MS) são observados. ${ }^{32}$ Para isso, etapas de atomização e excitação devem ser eficientes, enquanto os processos de supressão (quando a energia do estado excitado é convertida em energia translacional ou transferida para espécies que colidiram com átomo excitado) devem ser minimizados. Diferentes atomizadores e fontes de radiação podem ser utilizados em AFS, assim gerando diferentes cenários de BG. Chamas ar/acetileno apresentam alto BG devido à formação de radicais (e.g. $\mathrm{OH}, \mathrm{C}_{2}, \mathrm{CH}$ e $\mathrm{CN}$ ), resultando em elevados LODs. Por outro lado, as chamas baseadas na mistura de argônio e hidrogênio são recomendadas devido às menores emissões de BG. Apesar da relativa baixa temperatura, essas chamas são utilizadas com eficiência, mais especificamente em atomizadores empregados em sistemas comerciais associados à geração de hidretos. ${ }^{30} \mathrm{O}$ acoplamento da fluorescência induzida por laser a atomizadores eletrotérmicos combina vantagens como a elevada intensidade da fonte de radiação, que favorece a maior população de espécies excitadas, e o confinamento da nuvem atômica no interior do tubo. Nesse caso, o BG é principalmente constituído de emissão de corpo negro e radiação difusa da fonte primária. ${ }^{33} \mathrm{Na}$ análise de amostras com matrizes complexas, a fluorescência molecular, fluorescência atômica de concomitantes e espalhamento de radiação também contribuem para o BG. Medições baseadas em fluorescência não ressonante reduzem a contribuição do espalhamento e da radiação difusa; a detecção em comprimentos de onda acima de $300 \mathrm{~nm}$ reduz a contribuição da radiação de corpo negro emitida pelo atomizador. Assim como em GFAAS, o corretor de fundo baseado no efeito Zeeman é o único capaz de medir o BG no comprimento de onda analítico, podendo assim corrigir o sinal analítico obtido através da subtração da intensidade do BG; é também o único capaz de corrigir BG estruturado. Uma alternativa é dessintonizar o comprimento de onda do laser e medir apenas o BG durante a etapa de atomização. Em seguida, o BG é subtraído do sinal analítico total. Entretanto, essa estratégia, bem como o emprego de detectores multicanais, são válidas apenas para a correção de emissão de corpo negro e radiação difusa do laser. Empregando um detector multicanal, é possível medir simultaneamente o sinal total e o BG em comprimentos de onda distintos. Essa estratégia instrumental também permite corrigir os efeitos de ruídos originados da fonte de laser. ${ }^{33}$

\section{Espectrometria de massas com plasma acoplado indutivamente}

Proposto por Houk et al., em 1980, ${ }^{34}$ o acoplamento de um ICP a um espectrômetro de massas resultou em uma das mais poderosas técnicas para análise elementar. Íons positivos gerados no plasma à pressão atmosférica são extraídos através de cones de amostragem e skimmer para uma zona de alto vácuo, na qual as lentes de focalização, o analisador de massas e o detector estão localizados.

O número de isótopos estáveis é significativamente menor do que o número de linhas de emissão para um mesmo elemento, resultando em espectros de massas significativamente mais simples do que os espectros de emissão (Tabela 2) ${ }^{35}$ Essa característica leva à maior detectabilidade (e.g. LODs 40 e 100 vezes mais baixos foram obtidos para determinação de $\mathrm{Cd}$ e Mo, respectivamente, em comparação com ICP OES com configuração axial). ${ }^{22}$

Os fótons emitidos no plasma, que poderiam originar um intenso BG, são impedidos de atingir o detector, utilizando diferentes arranjos instrumentais. Em instrumentos com geometria linear, o fóton-stop (pequena placa metálica localizada atrás do cone skimmer que bloqueia os fótons e espécies neutras) e o deslocamento do analisador de massas e detector fora do eixo do feixe de íons eram os arranjos mais utilizados. ${ }^{36}$ Instrumentos com montagem em $90^{\circ}$ foram mais recentemente propostos e utilizam um anel vazado, o qual produz um campo eletrostático parabólico que reflete os íons para analisador de massas (posicionado $90^{\circ}$ em relação ao plasma), enquanto fótons e espécies neutras passam através do anel..$^{36,37}$ 
O BG remanescente em ICP-MS é causado por outras espécies carregadas positivamente (e.g. dímeros, óxidos, íons poliatômicos e de dupla carga) formadas a partir do gás do plasma, ar atmosférico ou solvente. O BG intrínseco à técnica é observado quando apenas água é introduzida no ICP-MS com plasma de argônio. ${ }^{38}$ Íons atômicos ou poliatômicos de argônio, nitrogênio e oxigênio podem causar sobreposições espectrais e resultados analíticos errôneos. Exemplos incluem sobreposições de ${ }^{14} \mathrm{~N}_{2}+{ }^{16} \mathrm{O}_{2}+{ }^{40} \mathrm{Ar}^{+},{ }^{40} \mathrm{Ar}^{16} \mathrm{O}^{+},{ }^{40} \mathrm{Ar}_{2}{ }^{+}$na determinação de ${ }^{28} \mathrm{Si}^{+},{ }^{32} \mathrm{~S}^{+},{ }^{40} \mathrm{Ca}^{+},{ }^{56} \mathrm{Fe}^{+} \mathrm{e}^{80} \mathrm{Se}^{+}$, respectivamente. Os ácidos também afetam os espectros do $\mathrm{BG}$ e isso deve ser considerado na escolha da estratégia de preparo de amostras em função dos isótopos a serem monitorados. ${ }^{39}$

O BG pode ser contornado utilizando a condição de plasma frio, monitorando um isótopo diferente ou utilizando correções matemáticas, mas essas estratégias não são universalmente aplicáveis e também apresentam algumas desvantagens. Sob condições de plasma frio, ao invés da predominância de espécies de argônio

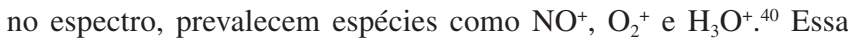
estratégia é particularmente eficaz para as determinações de $\mathrm{Fe}$ e Ca devido à atenuação do $\mathrm{BG}$ proveniente de ${ }^{40} \mathrm{Ar}^{16} \mathrm{O}^{+}$e ${ }^{40} \mathrm{Ar}^{+}$, respectivamente. Alternativamente, as celas de reação e/ou colisão, contendo multipolos, são as estratégias mais utilizadas. O feixe de íons é direcionado para a cela posicionada entre as lentes iônicas e o analisador de massas. Gases inertes ou reativos são introduzidos nas celas resultando em transferência de carga, fragmentação por colisão, retardo cinético, bem como reações do gás adicionado com o analito ou com o íon que gera o sinal de fundo. ${ }^{41}$

Em células de colisão, a redução do BG é baseada na discriminação de energia cinética. Íons de baixa energia são rejeitados pela barreira de energia potencial localizada na saída da cela, enquanto íons com maior energia cinética atingem o quadrupolo. Através da introdução de um gás inerte na cela de colisão (e.g. He), as energias cinéticas dos íons poliatômicos são preferencialmente reduzidas em comparação com os íons atômicos, devido às suas maiores seções transversais de colisão. Reações entre íons e gases de cela ocorrem quando gases tais como $\mathrm{NH}_{3}, \mathrm{O}_{2}, \mathrm{ou} \mathrm{CH}_{4}$ são introduzidos na cela de reação. A conversão do íon poliatômico que gera $\mathrm{BG}$ em espécies de razão $\mathrm{m} / \mathrm{z}$ diferente do analito ou em espécies neutras pode ocorrer com base nos parâmetros cinéticos e termodinâmicos. A formação de um novo íon a ser monitorado também é possível, tal como exemplificado na determinação de $\mathrm{S}$ e $\mathrm{P}$ monitorando $\mathrm{SO}^{+}$e $\mathrm{PO}^{+}$, respectivamente. ${ }^{42}$ Essas abordagens podem ser exploradas para a minimização do BG intrínseco à técnica, bem como para superar interferências

Recentemente proposta, a técnica de ICP-MS com configuração em tandem (ICP-MS/MS) inclui um analisador de massas quadrupolar (Q1) antes do sistema de reação octopolar $\left(\mathrm{ORS}^{3}\right)$ e o analisador de massas quadrupolar (Q2). Tanto razões $\mathrm{m} / \mathrm{z}$ iguais quanto diferentes podem ser selecionadas em Q1 e Q2, permitindo a operação em modos on-mass ou de deslocamento de massas, respectivamente. Em ambos os casos, é possível rejeitar todos os íons de razão m/z diferente do analito de interesse em Q1, o que resulta em melhor controle das reações ou processos colisionais no $\mathrm{ORS}^{3}$. O modo on-mass é normalmente usado quando íons causadores de BG reagem ou colidem com gás introduzido na cela, enquanto em modo de deslocamento de massas o íon do analito reage com o gás da cela formando um novo ín a ser monitorado. A principal vantagem do modo de deslocamento de massas em ICP-MS/MS é a eliminação de BG na razão $\mathrm{m} / \mathrm{z}$ do íon do produto de reação por Q1. Essa estratégia minimiza BG, evita interferências isobáricas provenientes de matriz e melhora os LODs.

Espectrômetros de massas de setor magnético e dupla focalização resolvem a sobreposição de BG e sinais analíticos pela combinação de um analisador de massas de setor magnético e um analisador eletrostático. ${ }^{43} \mathrm{O}$ poder de resolução é significativamente maior em comparação com instrumentos com quadrupolo (aproximadamente 10.000 versus 300). Por outro lado, essa instrumentação é mais complexa e cara do que aquela de instrumentos com quadrupolo e a sensibilidade é diminuída com o aumento da resolução.

\section{ESPECTROMETRIA MOLECULAR}

\section{Espectrofotometria UV-vis e fotoluminescência}

Nas técnicas espectrométricas moleculares, BG não é claramente definido como em espectrometria atômica. De fato, esse termo não é tão usual nessas técnicas, mas a diferenciação entre sinais analíticos e espúrios é também essencial para assegurar resultados confiáveis.

Tanto a espectrofotometria UV-vis, quanto as técnicas analíticas de fotoluminescência (i.e. fluorescência e fosforescência) são baseadas na absorção de radiação e essencialmente utilizam os mesmos tipos de fotodetectores. A princípio, todas as espécies fotoluminescentes podem também ser quantificadas por espectrofotometria, embora o inverso não seja necessariamente verdadeiro. Enquanto a espectrofotometria UV-vis é baseada na atenuação de um feixe de radiação (situação caracterizada por alto BG), as técnicas de fotoluminescência são baseadas na medida de fótons emitidos por espécies fotoexcitadas, em condições de BG extremamente baixos (i.e. fotodetectores inicialmente na ausência de radiação incidente). A analogia das velas em um estádio lotado (ver Figura 2) também se aplica nessa comparação. Em consequência dos diferentes princípios de medida, LODs até 3 ordens de magnitude inferiores podem ser obtidos em fotoluminescência. Essa discussão também pode ser estendida à comparação entre turbidimetria (baseada na atenuação de um feixe de radiação por espalhamento de radiação) e nefelometria, que envolve a medida da radiação espalhada pelas partículas em suspensão. É importante ressaltar que, no caso na turbidimetria e nefelometria, devido ao tamanho das partículas sólidas envolvidas, a frequência da radiação não se altera pelo processo de espalhamento, i.e. trata-se de espalhamento elástico. Aplicações analíticas de quimiluminescência são também baseadas em medições em condições de baixo BG, o que também resulta em baixos valores de LODs, apesar dos baixos rendimentos quânticos, e.g. 1,23\% para os sistemas utilizando luminol, ${ }^{44}$ bastante usuais em Química Analítica. Nessa técnica, a energia para a excitação das moléculas é proveniente de um processo reacional exotérmico e a relaxação ocorre com a emissão de fótons.

$\mathrm{O} \mathrm{BG}$ em fotoluminescência deve-se principalmente à radiação espúria (e.g. luz ambiente ou radiação proveniente da fonte de excitação que atinge o detector) e à corrente de escuro (dark current). A principal fonte de radiação espúria refere-se à emissão da fonte no comprimento de onda de excitação, que atinge o detector devido a processos de espalhamento (e.g. por partículas em suspensão) e à radiação em comprimentos de onda distintos dos de excitação, que deixam o monocromador devido a imperfeições na rede de difração e reflexões em outros componentes ópticos. ${ }^{45}$ São também relevantes os efeitos da transmissão de radiação em ordens superiores (especialmente de segunda ordem) e, em alguns casos, os sinais devidos ao espalhamento Raman, que se refere ao espalhamento inelástico, ou seja, com alteração de frequência relacionada aos níveis de energia moleculares ${ }^{46} \mathrm{Na}$ prática, devido à intensidade relativamente baixa, o efeito de espalhamento Raman, quando observado, refere-se somente ao solvente. Desta forma, conforme ilustrado na Figura 4I, hipoteticamente a excitação de sulfato de quinino em uma solução aquosa acidificada, utilizando a emissão de uma lâmpada de vapor de mercúrio em $254 \mathrm{~nm}$, poderia resultar em um espectro contendo: (i) a banda de emissão de fluorescência, centrada em $450 \mathrm{~nm}$ (Figura 4Ia); (ii) sinais espúrios causados pela radiação proveniente 
da fonte (espalhamento elástico, i.e. Rayleigh) em $254 \mathrm{~nm}$ ( $1^{\mathrm{a}}$ ordem) e em $508 \mathrm{~nm}$ ( $2^{\mathrm{a}}$ ordem), Figura 4I, $\mathrm{b}_{1}$ e $\mathrm{b}_{2}$, respectivamente e (iii) sinais devidos ao espalhamento Raman da água (espúrios no caso da medida de fluorescência) em $278 \mathrm{~nm}$ ( $1^{\text {a }}$ ordem) e $556 \mathrm{~nm}$ ( $2^{\mathrm{a}}$ ordem), Figura $4 \mathrm{I}, \mathrm{c}_{1}$ e $\mathrm{c}_{2}$, respectivamente ${ }^{49}$ Para minimizar a incidência de radiação espalhada (e, portanto, o BG), o detector é usualmente posicionado perpendicularmente ao feixe de excitação. $\mathrm{O}$ monocromador secundário (ou monocromador de emissão) também tem a função de minimizar a radiação espúria que atinge o detector. Redes de difração holográficas apresentam menos imperfeições que aquelas produzidas mecanicamente e, usualmente, dispensam o uso de espelhos côncavos para a focalização do feixe de radiação; portanto, a radiação espúria proveniente dos monocromadores é minimizada pelo uso desses dispositivos. Outra alternativa consiste em utilizar monocromadores com duas redes de difração após a fonte de excitação. Apesar de eficiente, essa alternativa acarreta na diminuição da potência do feixe incidente e, portanto, da sensibilidade das medidas de fluorescência, que é diretamente proporcional à potência do feixe de excitação. Em relação à corrente de escuro, o desenvolvimento dos detectores objetivou a diminuição de efeitos térmicos, evitando a necessidade de resfriamento dos dispositivos.

O BG é também relevante nas medidas de fosforescência, em que um intervalo de tempo após a interrupção da irradiação da amostra é necessário para eliminar a contribuição da fluorescência (neste caso, um sinal espúrio), cuja relaxação tipicamente se completa em intervalos de ns. Essa alternativa resulta na melhoria da razão sinal/ ruído e pode também ser explorada para a medida de fluorescência de espécies com tempo de vida do estado excitado relativamente longos, como é o caso de alguns complexos de lantanídeos, cujos tempos de relaxação tipicamente encontram-se no intervalo de 0.01 a $10 \mathrm{~ms}^{47}$ Essa estratégia, ilustrada na Figura 4II, é denominada fluorescência resolvida no tempo. Um atraso na medição de fluorescência $\left(\mathrm{t}_{1}\right)$ após um pulso de radiação para a formação das espécies no estado excitado é bastante eficiente para eliminar a emissão de fluorescência de outras espécies com tempo de vida mais curto (Figura 4II, B) e, portanto, para diminuir o BG na medição do sinal analítico (Figura 4II, A). Conforme ilustrado pela área sombreada na Figura 4II, o tempo de integração $\left(\mathrm{t}_{2}\right)$ também afeta diretamente a razão sinal/ruído. A fluorescência resolvida no tempo é amplamente explorada para fins analíticos e um exemplo é a determinação enzimática de glicose utilizando o complexo de európio com tetraciclina como sonda. ${ }^{45}$

Outra potencial fonte de BG em fotoluminescência refere-se à emissão por outras espécies em solução (e.g. contaminantes presentes nos solventes), adsorvidas nas paredes das celas de medida ou, ainda, à gordura presente nas mãos do analista. $\mathrm{O}$ uso de solventes de alta pureza e a limpeza cuidadosa das celas é, portanto, indispensável nas medidas de fluorescência e fosforescência. Nesse sentido, cabe ressaltar que alguns detergentes normalmente utilizados na limpeza de vidrarias são fluorescentes e podem aumentar o nível de BG devendo, portanto, ser evitados.

$\mathrm{Na}$ espectrofotometria UV-vis, o desempenho analítico depende criticamente da estabilidade da fonte de radiação, o que resultou na proposta da configuração em duplo feixe. $\mathrm{O}$ detector pode ser saturado caso a radiação incidente seja excessiva, impedindo a detecção de espécies em baixas concentrações ou com baixa absortividade molar. Para a medição de baixos valores de absorvância (i.e. inferiores a 0,100), é fundamental minimizar a radiação espúria e minimizar e corrigir o efeito da corrente no escuro, ambas fontes de BG em espectrofotometria. A magnitude da radiação espúria também afeta a linearidade, visto que, rigorosamente, a lei de Lambert-Beer é obedecida somente para radiações monocromáticas. Dessa forma, a porcentagem de radiação espúria é um parâmetro de desempenho importante, que deve ser informado pelo fabricante e periodicamente avaliado pelo analista. Espalhamento de radiação por partículas sólidas ou reflexão nas interfaces da cela de medida são também fontes de sinais espúrios, usualmente evitados pela filtração das amostras e compatibilização das celas de medida da amostra e referência, pelo uso da mesma cubeta ou de cubetas tão similares quanto possível. Derivação do espectro de absorção é também útil para compensar efeitos de espalhamento de radiação e absorção por espécies interferentes (em inglês, denominada matrix background) ${ }^{48,49}$ como ilustrado na Figura 5. Essa alternativa é baseada na relação inversa entre a magnitude do espectro derivado e a largura de banda do espectro de absorção (Figura 5a). É possível eliminar o efeito de espalhamento de radiação quando esse varia linearmente com o comprimento de onda (Figura 5b).

Medidas espectrofotométricas são afetadas pelo índice de refração, que deve ser mantido constante em todas as soluções (i.e. brancos analíticos e soluções de referência e de amostras). Quando detectores espectrofotométricos são acoplados a análises em fluxo ou HPLC, a inerente formação de gradientes de concentração pode também resultar em mudanças de índice de refração (efeito Schlieren).$^{50}$ Os sinais espúrios usualmente afetam a precisão e a exatidão em análises em fluxo e efeitos similares podem ser observados em cromatografia líquida caso haja sobreposição da frente de solvente com os picos analíticos. Espectrofotometria em duplo comprimento de onda é uma
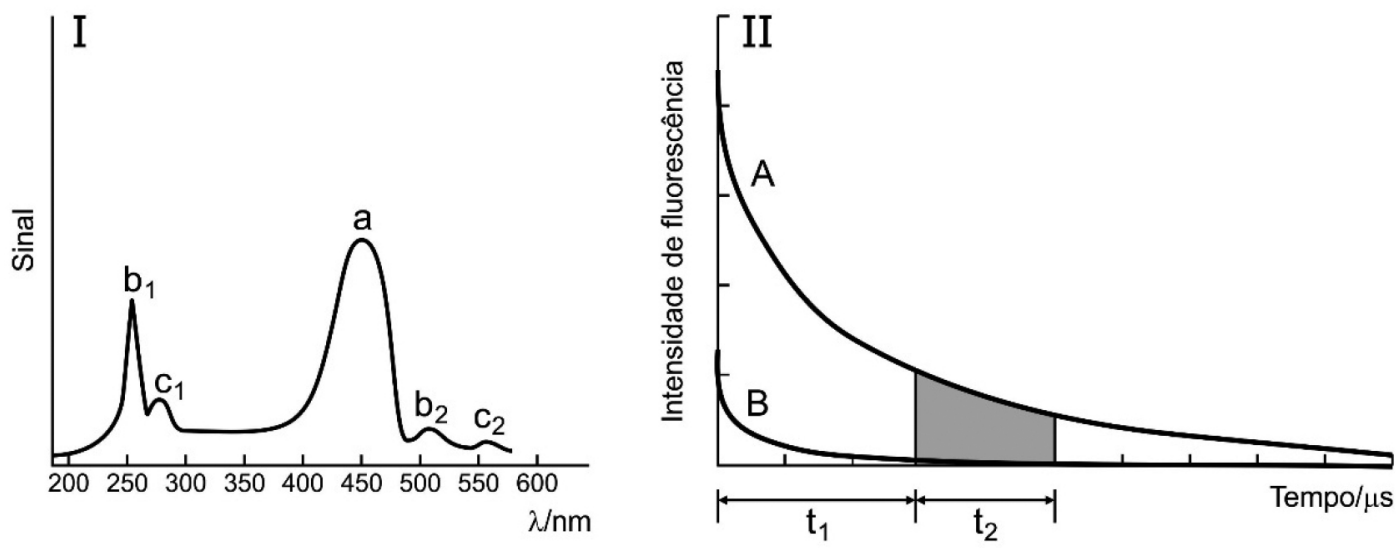

Figura 4. I. Espectro hipotético de fluorescência de uma solução aquosa de sulfato de quinino em meio ácido com excitação em $254 \mathrm{~nm}$ : a-emissão de fluorescência; $b_{1}$ e $b_{2}$-sinais de espalhamento elástico - $1^{a}$ e $2^{a}$ ordem, respectivamente e $c_{1}$ e $c_{2}$-bandas de espalhamento Raman da água $-1^{a}$ e $2^{a}$ ordem, respectivamente. II. Ilustração da fluorescência resolvida no tempo para minimizar BG: $t_{1}$ - tempo de atraso; $t_{2}$ - tempo de integração; A: decaimento da fluorescência do analito ou sonda fluorescente e B: decaimento do BG. Figuras 4 I e $4 I I$ adaptadas das referências 46 e 47, respectivamente 


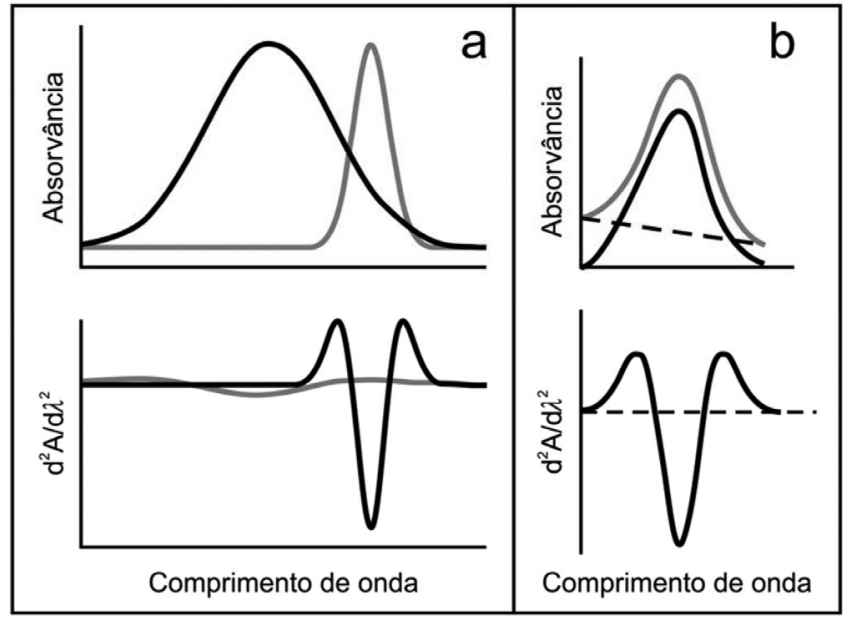

Figura 5. Representação da derivação do espectro de absorção (segunda derivada) para compensar $B G$ e interferências espectrais: (a) eliminação da absorção do $B G$ (espectro em cinza) e (b) do espalhamento de radiação; o espectro de absorção do analito (em preto) é deslocado pelo efeito de espalhamento de radiação por partículas sólidas em suspensão, resultando no espectro em cinza. A parte de baixo da Figura ilustra a correção utilizando a segunda derivada)

alternativa eficiente para a correção da perturbação, assim como de outros efeitos de absorção de fundo. Para tanto, a magnitude do sinal espúrio deve ser similar nos comprimentos de onda analítico e de referência. ${ }^{51}$ Em análises em fluxo, sempre que possível, as características físico-químicas do transportador são compatibilizadas com aquelas da amostra para evitar sinais espúrios, incluindo efeito Schlieren. O uso de elevados volumes de amostra (i.e. alguns mililitros) permite a separação dos sinais analíticos e espúrios. ${ }^{52}$ Por outro lado, efeito Schlieren pode ser explorado para fins analíticos, como na determinação de adulterações em bebidas alcoólicas, ${ }^{53}$ o que ilustra que BG pode também gerar informações úteis.

\section{TÉCNICAS DE SEPARAÇÃO}

\section{Detectores em cromatografia a gás}

Cromatografia a gás (GC) normalmente utiliza colunas capilares, que se destacam por possibilitar melhor resolução e separações mais rápidas, porém com baixa capacidade de amostra. Consequentemente, são necessários detectores com alta detectabilidade, o que pode ser alcançado com baixos sinais de fundo.

O detector por ionização em chama (FID), um dos mais usuais em GC, permite detectar a maioria das espécies orgânicas (exceto alguns compostos carbonílicos, álcoois e aminas) com limites de detecção na faixa de pg. ${ }^{54}$ Esse método de detecção é baseado na queima dos analitos em uma chama de hidrogênio, a qual é posicionada entre dois eletrodos com um potencial aplicado na faixa de 300-400 V. A combustão gera espécies carregadas (e.g. $\mathrm{CHO}^{+}$e elétrons) e, consequentemente, uma corrente elétrica proporcional ao número de átomos de carbono. A eficiência desse processo é extremamente baixa (ca. $10^{6}$ átomos resultam em uma espécie carregada, ${ }^{55}$ resultando em correntes na faixa de pA antes da amplificação), o que é aparentemente contraditório com os baixos LODs usualmente alcançados com FID. Contudo, isso pode ser entendido considerando que a combustão do hidrogênio gera poucas espécies carregadas, resultando em correntes de fundo (BG) extremamente baixas, causadas principalmente por impurezas no $\mathrm{H}_{2}$ e no gás de arraste. Nessa situação, poucas espécies carregadas podem ser detectadas da mesma forma em que poucos fótons podem ser medidos por um fotodetector no escuro. FID é, portanto, um outro exemplo de como baixos BG permitem alta detectabilidade, mesmo quando os processos envolvidos na geração do sinal analítico são pouco eficientes.

Espectrômetros de massas (MS) são outros importantes detectores utilizados em GC, que também ilustram como baixos BG podem resultar em baixos LODs. Isso é especialmente verdadeiro no modo de monitoramento seletivo de íons que, adicionalmente, diminui o sinal de fundo (ver discussão anterior sobre espectrometria de massas). Por outro lado, os detectores de captura de elétrons (ECD) são fundamentados no decréscimo de corrente quando espécies com alta afinidade eletrônica são eluídas da coluna. Ao contrário do FID e MS, a alta sensibilidade do ECD não é atribuída ao baixo BG, mas à alta eficiência de captura de elétrons (LODs para espécies halogenadas estão na faixa de fg, por exemplo). ${ }^{54}$ De fato, espécies que não apresentam alta afinidade eletrônica geram baixa sensibilidade ou não são detectadas. Outra característica importante é a estabilidade da corrente de elétrons no ECD, gerada por um emissor de radiação $\beta\left(\right.$ e.g. ${ }^{63} \mathrm{Ni}$ ), que promove a ionização de um gás (usualmente $\mathrm{N}_{2}$ ).

\section{Cromatografia líquida e eletroforese capilar}

O desempenho analítico em cromatografia a líquido e eletroforese capilar é também afetado por BG. MS e espectrometria de massas em tandem permitem alcançar os menores LODs devido aos valores extremamente baixos de BG. Por outro lado, o uso de algumas fases móveis é limitado pelos valores relativamente altos de BG, por exemplo, solventes que apresentam alta absortividade no comprimento de onda de medida quando se utiliza detecção espectrofotométrica. Nesse caso, os comprimentos de onda de corte (do inglês cutoff wavelength) indicam os valores mínimos de comprimentos de onda que podem ser utilizados na detecção, sem gerar absorção excessiva pela própria fase móvel. Outro aspecto interessante é a detecção indireta em eletroforese capilar, em que as medições são conduzidas em condições de BG elevado (e.g. alta condutividade ou fluorescência). Como a concentração dos íons ou fluoróforos é constante, uma resposta estável é gerada no detector. A zona contendo o analito então diminui a resposta do detector, permitindo a quantificação. ${ }^{56}$ Estratégia similar é adotada em procedimentos espectrofotométricos baseados em descolorimetria, no qual a base de medida é a diminuição da absorção devido à reação química do reagente (espécie absorvente) como o analito. ${ }^{57}$

\section{MÉTODOS ELETROANALÍTICOS}

\section{Condutometria}

A condutometria também ilustra o efeito de baixos valores de BG sobre a detectabilidade. Baixas concentrações de íons podem ser detectadas devido à condutividade negligenciável do solvente puro (usualmente água). Devido à inerente falta de seletividade, a condutometria é analiticamente útil somente quando acoplada a técnicas de separação, tais como cromatografia iônica (IC), eletroforese capilar, ou difusão gasosa em sistemas de análises em fluxo, ou para detectar o ponto final de titulações. Alguns artifícios são frequentemente utilizados para a diminuição de BG. Por exemplo, o desempenho analítico em IC é significativamente melhorado utilizando colunas supressoras. Esse importante desenvolvimento, apresentado em 1975, foi decisivo para que a condutometria se tornasse o detector mais usual em IC. ${ }^{58}$ No processo de supressão, os íons da fase móvel são trocados por $\mathrm{H}^{+}$e $\mathrm{OH}^{-}$em quantidades estequiométricas, resultando na formação de água e diminuindo a condutividade de fundo (originalmente denominado eletrólito de fundo, do inglês background electrolyte). Em 
instrumentos modernos, por exemplo, íons $\mathrm{Na}^{+}$em concentração de $0,1 \mathrm{~mol} \mathrm{~L}^{-1}$ são completamente removidos de uma solução fluindo a 2,0 $\mathrm{mL} \mathrm{min}^{-1} \cdot{ }^{5}$ A supressão de íons do eletrólito viabiliza a detecção de íons da amostra, cujas concentrações são significativamente inferiores àquelas do eluente (concentrações de $\mathrm{mg} \mathrm{L}^{-1}$ ). Um efeito análogo é observado em sistemas de análises em fluxo com difusão gasosa, nos quais a solução absorvedora e, portanto, o detector condutométrico, é, usualmente, separada da solução doadora por uma membrana hidrofóbica, permeável a gases. Dessa forma, o detector está em contato com um meio com condutividade extremamente baixa (i.e. baixo BG). Espécies voláteis ou volatilizáveis por meio de reações químicas (e.g. $\mathrm{NH}_{4}{ }^{+}, \mathrm{CO}_{3}{ }^{2-}, \mathrm{CN}^{-}$e $\mathrm{S}^{2-}$ ) podem difundir através da membrana e sofrer ionização no fluxo absorvedor, permitindo a detecção indireta, apesar da baixa eficiência do processo de difusão (tipicamente $<5 \%$ ). Uma estratégia similar é adotada em biossensores, nos quais a amostra é separada dos eletrodos (e.g. detecção potenciométrica ou amperométrica) por uma membrana, na qual enzimas são imobilizadas. Os produtos reacionais são então detectados em uma condição de BG extremamente baixos, independentemente da composição da amostra.

\section{Potenciometria}

Potenciometria é baseada na medida da diferença de potencial (E) entre os eletrodos indicador e de referência. Essa diferença de potencial é uma medida da tendência de ocorrência de uma reação química redox, com negligenciável fluxo de corrente através do sistema, devido à alta impedância do amplificador operacional do potenciômetro. A correlação de E com a concentração do analito. por meio da equação de Nernst, requer que as outras fontes de diferença de potencial sejam desprezíveis (i.e. baixo BG). Contribuição significativa à diferença de potencial pode resultar dos potenciais de junção, os quais são usualmente minimizados utilizando uma ponte salina com íons com mobilidade similar (e.g. $\mathrm{KCl}$ ). Outra importante fonte de BG em potenciometria é o potencial de assimetria observado em eletrodos de vidro, mas isso pode ser compensado com uma calibração adequada.

Potenciometria e, em menor extensão, condutometria, amperometria e espectrofotometria, são frequentemente utilizadas na detecção do ponto final de titulações. Uma vez que somente as variações nas propriedades físico-químicas são importantes, o BG inicial não afeta a detecção do ponto final da titulação. Dessa forma, o potencial inicial, a condutividade ou a coloração da amostra não afetam a exatidão em detecção potenciométrica, condutométrica e espectrofotométrica, respectivamente. Uma comparação deve ser feita com a dificuldade de detecção visual do ponto final de titulações de amostras turvas ou bastante coloridas.

\section{Voltametria}

Voltametria engloba diversos métodos eletroquímicos baseados na transferência de elétrons entre os eletrodos e a solução, promovendo processos redox nas interfaces eletrodo-solução. Nesses métodos, em função do potencial aplicado, a corrente elétrica devida aos processos de transferência de elétrons (denominados processos Faradaicos) é medida. $\mathrm{O}$ potencial aplicado pode ser mantido fixo (medidas amperométricas) ou variado de diversas formas. Uma diversidade de eletrodos é disponível e a seleção depende do analito a ser detectado e da amostra a ser analisada. É possível alcançar excelente sensibilidade em diversas aplicações, quando a técnica é utilizada de forma adequada. ${ }^{59}$ Para tanto, o foco é estabelecer condições para que a transferência de massa na solução seja controlada por difusão na superfície dos eletrodos e os processos não Faradaicos sejam eliminados ou minimizados. Esses processos, que geram o BG nas técnicas voltamétricas, não envolvem a transferência de elétrons entre os eletrodos e a solução e devem-se à formação da dupla camada elétrica na interface eletrodo-solução. ${ }^{59} \mathrm{O}$ efeito é usualmente minimizado pela adição de um eletrólito de suporte ou pelo uso das técnicas de pulso. Após aplicar um pulso de potencial, a corrente faradaica diminui devido à limitação difusional do transporte de massa, enquanto a corrente não faradaica decai exponencialmente a zero. A aquisição de sinal é feita no instante correspondente à máxima diferença entre as correntes (i.e. na condição relativa de máxima transferência de elétrons por processos redox e mínimo sinal de fundo devido a processos secundários).

\section{COMENTÁRIOS FINAIS}

Em análises instrumentais, a medida confiável dos sinais analíticos depende da diminuição e correção apropriada dos sinais espúrios. Para tanto, estratégias eficientes têm sido desenvolvidas, muitas delas discutidas neste artigo didático. A eliminação (ou modificação) de componentes da matriz durante o preparo das amostras é a primeira estratégia a ser considerada. A melhoria instrumental (incluindo a aquisição de sinais) no sentido de diferenciar os sinais analíticos e espúrios tem sido essencial para determinações analíticas bem sucedidas, especialmente na análise de traços e ultra-traços.

Enquanto em algumas técnicas analíticas as fontes de sinais de fundo são bem definidas e estratégias adequadas são disponíveis para minimização e correção, outras técnicas ainda requerem estudos adicionais. $\mathrm{O}$ melhor entendimento dos processos pode melhorar significativamente o desempenho analítico dessas técnicas. É também possível que informações obtidas a partir do BG sejam exploradas para fins analíticos, incluindo a obtenção de informações adicionais sobre a amostra, além de impulsionar o desenvolvimento instrumental.

\section{AGRADECIMENTOS}

Os autores agradecem à FAPESP (Processos 2011/23498-9 e 2013/26857-5), CNPq (Processos 303107/2013-8 e 308721/2013-6) e CAPES pelas bolsas e auxílios à pesquisa e a L. C. Nunes por ter fornecido os dados referentes à detecção por LIBS. Esta é uma contribuição do Instituto Nacional de Ciências e Tecnologias Analíticas Avançadas.

\section{REFERÊNCIAS}

1. Lundell, G. E. F.; Ind. Eng. Chem., Anal. Ed. 1933, 5, 221.

2. Donati, G. L.; Amais, R. S.; Nóbrega, J. A.; Spectroscopy 2012, 27, 44.

3. http://goldbook.iupac.org/PDF/goldbook.pdf, acessada em outubro de 2016.

4. Thomas, R.; Spectroscopy 2002, 17, 36.

5. Holler, F. J.; Skoog, D. A.; Crouch S. R.; Princípios de Análise Instrumental, $6^{\mathrm{a}}$ ed., Bookman: Porto Alegre, 2009.

6. Koirtyohann, S. R.; Pickett, E. E.; Anal. Chem. 1965, 37, 601.

7. Slavin, W.; Manning, D. C.; Carnrick, G. R.; At. Spectrosc. 1981, 2, 137.

8. Bulska, E. Em Encyclopedia of Analytical Chemistry; Meyers, R. A., ed.; Wiley-VCH: Weinheim, 2009.

9. Welz, B.; Sperling, M.; Atomic Absorption Spectrometry, $3^{\text {rd }}$ ed.; WileyVCH: Weinheim, 1997

10. Smith, S. B.; Hieftje, G. M.; Appl. Spectrosc. 1983, 37, 419.

11. Stephens, R.; Ryan, D. E.; Talanta 1975, 22, 659.

12. Bermejo-Barrera, P.; Moreda-Piñeiro, J.; Moreda-Piñeiro, A.; BermejoBarrera, A.; Microchim. Acta 1998, 128, 215.

13. Welz, B.; Vale, M. G. R.; Pereira, E. R.; Castilho, I. N. B.; Dessuy, M. B.; J. Braz. Chem. Soc. 2014, 25, 799. 
14. Harris, D. C.; Quantitative Chemical Analysis, $6^{\text {th }}$ ed., W.H. Freeman and Company: New York, 2003.

15. Rust, J. A.; Donati, G. L.; Afonso, M. T; Nóbrega, J. A.; Jones, B. T.; Spectrochim. Acta, Part B 2009, 64, 191.

16. de Loos-Vollebregt, M. T. C.; van Ochten, P. J.; J. Anal. At. Spectrom. 1990, 5,183

17. Olesik, J. W.; Anal. Chem. 1991, 63, 12A.

18. Miller, M. Em Inductively Coupled Plasmas in Analytical Atomic Spectroscopy; Montaser, A.; Golightly, D. W., eds.; VCH Publisher: New York, 1992; pp. 54.

19. Nölte, J.; ICP Emission Spectrometry, A Practical Guide; $1^{\text {st }}$ ed.; WileyVCH: Weinheim, 2003.

20. Abdallah, M. H.; Diemiaszonek, R.; Jarosz, J.; Mermet, J. M.; Robin, J.; Trassy, C.; Anal. Chim. Acta 1976, 84, 271.

21. Silva, J. C. J.; Santos, D. M.; Cadore, S.; Nóbrega, J. A.; Baccan, N.; Microchem. J. 2004, 77, 185.

22. Hill, S. J.; Fisher, A.; Foulkes, M. Em Inductively Coupled Plasma Spectrometry and its Applications, Handley, A. J.; Chalmers, J. M., eds.; Blackwell Publishing Ltd.: Oxford, 2007; pp. 67.

23. Rust, J. A.; Nóbrega, J. A.; Calloway Jr., C. P.; Jones, B. T.; Spectrochim. Acta Part B 2005, 60, 589 .

24. Rust, J. A.; Nóbrega, J. A.; Calloway, C. P.; Jones, B. T.; Spectrochim. Acta, Part B 2006, 61, 255.

25. Santos, L. N.; Gonzalez, M. H.; Moura, M. F.; Donati, G. L.; Nóbrega, J. A.; Talanta 2012, 97, 285.

26. Gonzalez, M. H.; Santos, L. N.; Nóbrega, J. A.; Rocha, F. R. P.; Quim. Nova 2010, 33, 2266.

27. Pasquini, C.; Cortez, J.; Silva, L. M. C.; Gonzaga, F. B.; J. Braz. Chem. Soc. 2007, 18, 463.

28. Santos Jr., D.; Nunes, L. C.; Trevizan, L. C.; Godoi, Q.; Leme, F .O.; Braga, J. W. B.; Krug, F. J.; Spectrochim. Acta, Part B 2009, 64, 1073.

29. Winefordner, J. D.; J. Chem. Educ. 1978, 55, 72.

30. Cai, Y.; In Encyclopedia of Analytical Chemistry, Meyers, R. A., ed.; Wiley-VCH: Weinheim, 2000.

31. Stockwell, P. B.; Corns, W. T.; Allen, J.; J. Anal. At. Spectrom. 2009, 24, 1026.

32. Gómez-Ariza, J. L.; Sánchez-Rodas, D.; Giráldez, I.; Morales, E.; Talanta 2000, 51, 257.

33. Sjostrom, S.; Spectrochim. Acta Rev. 1990, 13, 407.

34. Houk, R. S.; Fassel, V. A.; Flesch, G. D.; Svec, H. J.; Gray, A. L.; Taylor, C. E.; Anal. Chem. 1980, 52, 2283.
35. CRC Handbook of Chemistry and Physics; Haynes, W. M., ed.; $91^{\text {th }}$ ed., CRC Press: New York, 2010-2011.

36. Thomas, R. A.; Spectroscopy 2001, 16, 38.

37. Becker, J. S.; Inorganic Mass Spectrometry, Principles and Applications; Wiley-VCH: Chichester, 2007.

38. Horlick, G.; Montaser, A. Em Inductively Coupled Plasma Mass Spectrometry; $1^{\text {st }}$ ed.; Montaser, A., ed.; Wiley-VCH: Chichester, 1998, p. 519.

39. Tan, S. H.; Horlick, G.; Appl. Spectrosc. 1986, 40, 445.

40. Wollenweber, D.; Strassburg, S.; Wünsch, G.; Fresenius J. Anal. Chem. 1999, 364, 433

41. Tanner, S. D.; Baranov, V. I.; Bandura, D. R.; Spectrochim. Acta, Part B 2002, 57, 1361

42. Bandura, D. R.; Baranov, V. I.; Tanner, S. D.; Anal. Chem. 2002, 74, 1497.

43. Vanhaecke, F. Em Isotopic Analysis, Fundamentals and Applications Using ICP-MS; Vanhaecke, F.; Degryse, P., eds.; Wiley-VCH: Weinheim, 2012, pp. 38-43.

44. Lee, J.; Seliger, H. H.; Photochem. Photobiol. 1972, 15, 227.

45. Lakowicz, J. R.; Principles of Fluorescence Spectroscopy, $3^{\text {rd }}$ ed., Springer: New York, 2006.

46. Ingle Jr., J. D.; Crouch, S. R.; Spectrochemical Analysis, $1^{\text {st }}$ ed.; Prentice Hall: New Jersey, 1988.

47. Wu, M.; Lin, Z.; Durkop, A.; Wolfbeis, O. S.; Anal. Bioanal. Chem. 2004, 380, 619

48. Campanella, L.; Magrì, A. L.; Sorbo, A.; Tomassetti, M.; J. Pharm Biomed. Anal. 2002, 29, 1135.

49. Lau, O.; Luk, S.; Cheng, O.; Chiu, T. P. Y.; Analyst 1992, 117, 777.

50. Rocha, F. R. P.; Nóbrega, J. A.; Quim. Nova 1996, 19, 636.

51. Rocha, F. R. P.; Martelli, P. B.; Reis, B. F.; Anal. Chim. Acta 2001, 438, 11.

52. Rocha, F. R. P.; Nóbrega, J. A.; J. Braz. Chem. Soc. 1997, 8, 625.

53. Costa, R. S.; Santos, S. R. B.; Almeida, L. F.; Nascimento, E. C. L.; Pontes, M. J. C.; Lima, R. A. C.; Simões, S. S.; Araújo, M. C. U.; Microchem. J. 2004, 78, 27.

54. Westmoreland, D.G.; Rhodes, G. R.; Pure Appl. Chem. 1989, 61, 1147.

55. Holm, T.; J. Chromatogr. A 1999, 842, 221.

56. Zhang, M.; Qiu, D.; Kang, J.; Chromatographia 2015, 78, 833.

57. Pereira, A. C.; Reis, B. F.; Rocha, F. R. P.; Talanta 2015, 131, 21.

58. Small, H.; Stevens, T. S.; Bauman, W.C.; Anal. Chem. 1975, 47, 1801

59. Bard, A. J.; Faulkner, L. R.; Electrochemical Methods: Fundamentals and Applications, $2^{\text {nd }}$ ed., John Wiley \& Sons: New York, 2001. 